\title{
Heavy metals and community structure of microorganism changes during livestock manure composting with inoculation of effective microorganisms
}

\author{
Haibin Zhou ${ }^{1,2}$, Yujun Shen ${ }^{1,2}$, Ran $\mathrm{Li}^{1,2}$, Haibo Meng ${ }^{1,2^{*}}$, Xi Zhang ${ }^{1,2}$, Jian Wang ${ }^{1,2}$, \\ Hongsheng Cheng ${ }^{1,2}$, Shanshan Dong ${ }^{1,2}$, Liqiu Song ${ }^{1,2}$, Jingtao Ding ${ }^{1,2}$, Qiongyi Cheng ${ }^{1,2}$ \\ (1. Academy of Agricultural Planning \& Engineering, Ministry of Agriculture and Rural Affairs of the People's Republic of China, \\ Beijing 100125, China; \\ 2. Key Laboratory of Technologies and Models for Cyclic Utilization from Agricultural Resources, Ministry of Agriculture and \\ Rural Affairs of the People's Republic of China, Beijing 100125, China)
}

\begin{abstract}
Effective microorganisms (EM) is usually used in composting to improve the composting process. However, the effect of EM on heavy metals evolution was still unclear. This study was performed to illustrate the microbial community changes that occur during composting with the addition of EM and to determine the evolution of heavy metal speciation during this process. The requirement of harmlessness for pig manure was met after the addition of EM at a dosage of $0.5 \%$, with a germination index of $96.42 \%$. The bacterial and fungal diversity were both found to decrease during the composting process. Additionally, the bioavailability of $\mathrm{Cu}$ and $\mathrm{Pb}$ decreased significantly during composting. Significant correlations were observed between the microbial composition and the percentage of different heavy metals fractions; however, the mechanism responsible for this correlation requires further investigation. This study has the potential to contribute to control of heavy metal contamination during the process of recycling pig manure through the controlled addition of EM.
\end{abstract}

Keywords: effective microorganisms, heavy metal, microbial communities, pig manure, composting

DOI: $10.25165 /$ j.ijabe.20201306.5674

Citation: Zhou H B, Shen Y J, Li R, Meng H B, Zhang X, Wang J, et al. Heavy metals and community structure of microorganism changes during livestock manure composting with inoculation of effective microorganisms. Int $\mathbf{J}$ Agric \& Biol Eng, 2020; 13(6): 125-132.

\section{Introduction}

In 2016, the amount of poultry and livestock manure reached 3.8 billion tons ${ }^{[1]}$, approximately $40 \%$ of which had not been properly treated and disposed. Composting is one of the primary treatment methods for animal manure, which is inexpensive and effective. However, the addition of heavy metals to animal feed leads to residual heavy metals in animal manure in some regions in China ${ }^{[1,2]}$. Hence, the organic fertilizer produced from these sources of animal manure may lead to heavy metal contamination in the soil ${ }^{[3]}$, which has the potential to increase the risk of adverse health side effects in both agricultural products and the human

\section{Received date: 2020-07-28 Accepted date: 2020-09-10}

Biographies: Haibin Zhou, PhD, Senior Engineer, research interests: treatment and utilization of agricultural wastes, Email: zhouhaibin@ caaepd.org.cn; Yujun Shen, PhD, Professor, research interests: cyclic utilization from agricultural resources, Email: shenyujun@caaepd.org.cn; Ran Li, Assistant Engineer, research interests: fertilizer utilization of agricultural wastes, Email: liran@aape.org.cn; Xi Zhang, PhD, Senior Engineer, research interests: fertilizer utilization of agricultural wastes, Email: zhangxi@caaepd.org.cn; Jian Wang, $\mathrm{PhD}$, Senior Engineer, research interests: cyclic utilization from agricultural resources, Email: wangjian@ caaepd.org.cn; Hongsheng Cheng, PhD, Senior Engineer, research interests: cyclic utilization from agricultural resources, Email: chenghongsheng@caaepd.org.cn; Shanshan Dong, Engineer, research interests: cyclic utilization from agricultural resources, Email: dongshanshan@aape.org.cn; Liqiu Song, Senior Engineer, research interests: cyclic utilization from agricultural resources, Email: songliqiu@aape.org.cn; Jingtao Ding, PhD, Senior Engineer, research interests: cyclic utilization from agricultural resources, Email: dingjingtao@caaepd.org.cn; Qiongyi Cheng, Engineer, research interests: cyclic utilization from agricultural resources, Email: chengqiongyi@aape.org.cn. *Corresponding author: Haibo Meng, $\mathrm{PhD}$, Professor, research interests: biomass utilization. No.41, Maizidian Street, Chaoyang District, Beijing 100125, China. Tel: +86-10-59197288, Email: menghaibo@ caaepd.org.cn. body.

Some researches ${ }^{[4-6]}$ showed that the composting process may decrease the availability of heavy metals, and thus decrease the phytotoxicity of heavy metals before it is used in soil. Fungi such as Saccharomyces cerevisiae, Penicillium spp., and Aspergillus spp. were reported to reduce the bioavailability of $\mathrm{Zn}, \mathrm{Cu}$, and $\mathrm{Pb}$, through the complexation or absorption of heavy metal ions with their functional groups ${ }^{[7-9]}$. Say et al. ${ }^{[10]}$ showed that Phanerochaete chrysosporium exhibited high bio-adsorption for $\mathrm{Pb}$, $\mathrm{Cd}$, and $\mathrm{Cu}$ ions. Zeng et al. ${ }^{[11]}$ demonstrated that the inoculum obtained from white-rot fugus in solid waste compost increased lead $(\mathrm{Pb})$ levels within residual fractions to $70.5 \%$. Meanwhile, the addition of microbial may also improve humification. Microorganisms could reduce heavy metal bioavailability through multiple mechanisms including biological adsorption, heavy metal reduction, extracellular precipitation, and biological mineralization. The metal ions may be adsorbed by the carboxylic groups and phosphate anions on the bacterial cell wall. The addition of microorganisms may also improve the process of humification and inactivation of heavy metals. $\mathrm{Xi}$ et al. ${ }^{[12]}$ reported that microorganism inoculation of ammonia-oxidizing bacterium, Nitrobacter spp., Thiobacillus spp., and lignin decomposition composite microorganisms improved the efficiency and increased the quality of municipal solid wastes. The resulting humic substances may then adsorb metal ions via carboxyl functional groups and, thereby, reduce the bioavailability of heavy metals. Interestingly, Zheljazkov et al. ${ }^{[13]}$ showed that small molecules within humus may increase the effectiveness, while reducing the toxicity, and mobility of copper $(\mathrm{Cu})$ and zinc $(\mathrm{Zn})$. However, only a few reports have focused on the effect of multiple microbial species inoculant on the bioavailability of heavy metals during 
composting.

Effective microorganisms (EM) are efficient complexes of microbial flora including Saccharomycetes spp., Actinomycetes spp., Lactobacillus spp., etc. ${ }^{[14]}$, which have been widely used to control gaseous emissions, reduce composting time, and improve the humification process of composting ${ }^{[15,16]}$. Daur ${ }^{[17]}$ reported that the DTPA-extractable forms of $\mathrm{Cu}$ and $\mathrm{Zn}$ decreased during composting with addition of EM, which was attributed to the formation of organic matter-metal complexes. This research was to identify microbial changes that occur during composting with the inoculation of EM, and to characterize the evolution of heavy metals during the process. Thus, this study has the potential to contribute to control of heavy metal contamination during the process of recycling poultry and livestock manure.

\section{Materials and methods}

\subsection{Experiment design}

All experiments were conducted in the laboratories at the Academy of Agricultural Planning \& Engineering in Beijing, Daxing District, China. Pig manure was collected from a pig farm, and corn stalks were collected from surrounding farmland in Daxing District, Beijing. EM, which consisted of Lactobacillus spp., yeast species, Bacillus spp., photosynthetic bacteria, and Actinomycetes spp., was purchased from Shandong Yi'an Biotechnology Co., Ltd. The pig manure and approximately 1-cm-long maize stalks were mixed. The moisture content of the mixed material was adjusted to approximately $65 \%$, and the carbon/nitrate $(\mathrm{C} / \mathrm{N})$ was adjusted to approximately $25: 1$. The addition ratio of EM to the mixed material was $0.5 \%$ (wet basis). Composting was performed in a $60 \mathrm{~L}$ bench-scale composting bioreactor, according to the protocols outlined in the previous studies ${ }^{[6]}$. The physical and chemical characteristics of the raw materials are shown in Table 1.

Table 1 Physical and chemical characteristics of the raw materials

\begin{tabular}{cccccc}
\hline $\begin{array}{c}\text { Raw } \\
\text { materials }\end{array}$ & $\begin{array}{c}\text { Weight } \\
/ \mathrm{kg}\end{array}$ & $\begin{array}{c}\text { Moisture } \\
\text { content/\% }\end{array}$ & $\begin{array}{c}\text { Total carbon } \\
/ \%\end{array}$ & $\begin{array}{c}\text { Total nitrogen } \\
/ \%\end{array}$ & $\mathrm{C} / \mathrm{N}$ \\
\hline Pig manure & 24 & 66.34 & 8.82 & 0.566 & 15.58 \\
Maize stalk & 9 & 22.71 & 38.28 & 0.84 & 45.57 \\
Mix material & 35 & 65.79 & 5.56 & 0.21 & 26.31 \\
\hline
\end{tabular}

\subsection{Sampling and analysis}

In composting experiment, three samples were collected from plugs at different depths from the reactor, mixed thoroughly on days of $0,1,3,5,8,12,16,20$, and 30 of the composting process to test the $\mathrm{pH}$, electronic conductivity (EC), organic matter content, and the total concentration and distribution of $\mathrm{Cu}, \mathrm{Cd}, \mathrm{Zn}$, and $\mathrm{Pb}$. The temperature of each plug was measured using a temperature sensor (SBWZ-2460, Shanghai Hongtian Instrument Factory, China). The pile temperatures of the high, middle and low levels in the reactors were determined using an automatic temperature feedback control system every $15 \mathrm{~min}$ during composting. The samples were aliquoted into two, with one aliquot stored at $4{ }^{\circ} \mathrm{C}$, and the other used to characterize the content of heavy metals. Total heavy metal levels were analyzed using Inductively Coupled Plasma Atomic Emission Spectrometer (ICPE-9000, Shimadzu, Japan), and the distribution of different fractions of $\mathrm{Cu}, \mathrm{Zn}, \mathrm{Pb}$ and $\mathrm{Cd}$ was assessed using the modified BCR (European Communities Bureau of Reference) sequential extraction method ${ }^{[6]}$. The content of $\mathrm{Cu}, \mathrm{Zn}$, and $\mathrm{Pb}$ were directly analyzed using inductively coupled plasma optical emission spectrometry (Optima 5300DV, Perkin-Elmer). The content of $\mathrm{Cd}$ was analyzed using atomic absorption spectroscopic method (ContrAA700, Analytik Jena AG). The seed germination index (GI) was detected, using Chinese cabbage (Brassica parachinensis $)^{[18]}$, to evaluate the phytotoxicity of the composting mixtures according to protocols optimized in our previous study ${ }^{[6]}$ The moisture content was determined after each sample was dried at $105^{\circ} \mathrm{C}$ for $24 \mathrm{~h}$ in a hot-air oven. Volatile solid (VS) were measured following $6 \mathrm{~h}$ incubation at $550^{\circ} \mathrm{C}$ in a muffle furnace $^{[19]}$ to measure the organic matter content of the samples. Additionally, the Kjeldahl method was employed for the quantification of total nitrogen in the samples.

To identify the bacterial and fungal diversity during the composting process, eight samples (Day $0,1,3,5,8,12,16$, and 30) were collected and microbial DNA was extracted using the FastDNA® SPIN Kit for Soil (Mpbio, USA) according to manufacturer's protocols. The final DNA concentration and purity were determined using NanoDrop 2000 UV-vis spectrophotometer (Thermo Scientific, Wilmington, USA). The V3-V4 hypervariable regions of the bacteria 16S rRNA gene were amplified with a primers 338F 5'-ACTCCTACGGGAGGCAGCAG-3' and 806R 5'-GGACTACHVGGGTWTCTAAT-3' (Majorbio Bio-Pharm Technology Co., Shanghai, China). And primers ITS1F 5'-CTTGGTCATTTAGAGGAAGTAA-3' and ITS2 (2043R 5'-GCTGCGTTCTTCA TCGATGC-3') targeting regions of fungal ITS1 were used for fungal amplification.

The operational taxonomic units (OTUs) were determined according to the online instructions of the Quantitative Insights Into Microbial Ecology software ${ }^{[20]}$. OTUs were defined at the $97 \%$ similarity level using UCLUST clustering ${ }^{[21]}$. Differences among microbial communities were assessed using Bray-Curtis distances, followed by principal coordinate analysis (PCoA). To understand the richness of bacterial and fungal species at different periods of composting, Shannon and Simpson indices were determined using R3.1. ${ }^{[22]}$. A heatmap of Pearson correlation coefficients for the relationships between the percentage of different fractions of heavy metals, and microbial communities was conducted using the pheatmap package ${ }^{[23]}$.

\section{Result and discussion}

\subsection{Physicochemical property during composting}

Temperature is an important indicator of biological energy accumulation and the rate of organic matter degradation in the composting process. The peak temperature was reached on D3 and measured $58.3^{\circ} \mathrm{C}$, and the core temperature of the composting pile met the requirement that the temperature be maintained above $55^{\circ} \mathrm{C}$ for more than 3-5 d (Figure 1a). The moisture content of the pile decreased from $65.79 \%$ to $44.06 \%$ (Figure 1b), while the volatile solid was seen to decrease from $72.21 \%$ to $63.53 \%$ (Figure 1c). Additionally, the electrical conductivity (EC) is one of the factors reflective of the extract soluble salt content in composting material, which may be toxic to plants when the $\mathrm{EC}$ value is greater than $4.0 \mathrm{mS} / \mathrm{cm}$. Within the mesophilic phase the EC was observed to increase and then decreased to approximately $1.4 \mathrm{mS} / \mathrm{cm}$ where it remained stable. The $\mathrm{pH}$ also increased from 8.3 to approximately 9.2 (Figure $1 \mathrm{~d}$ ). At the completion of the composting period, the germination index was determined to be $96.42 \%$, which also met the requirement for harmlessness of pig manure. 


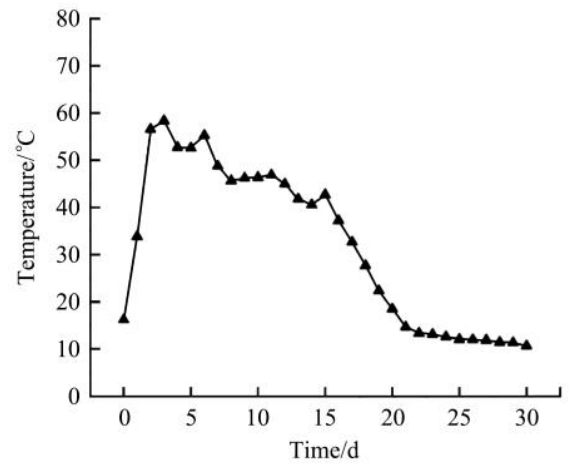

a. Temperature

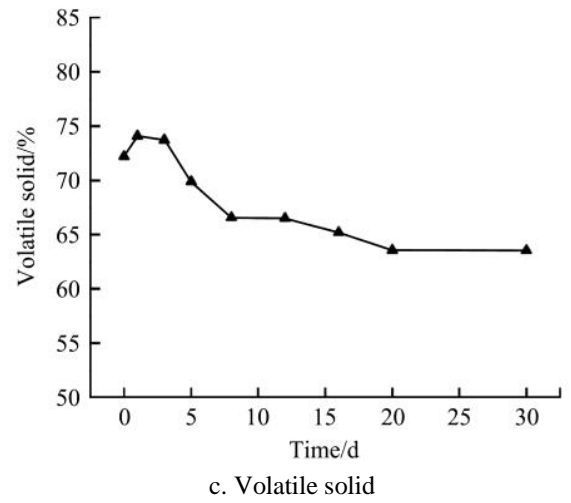

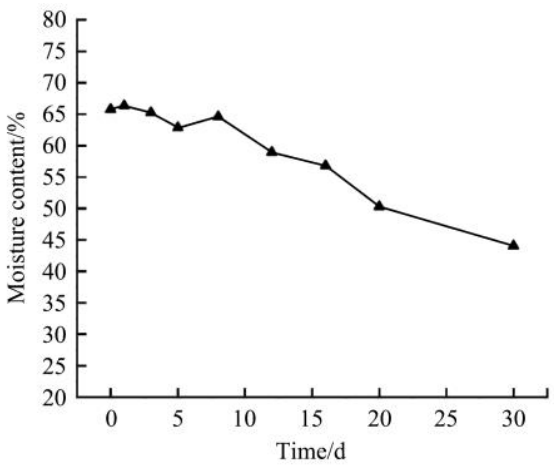

b. Moisture content

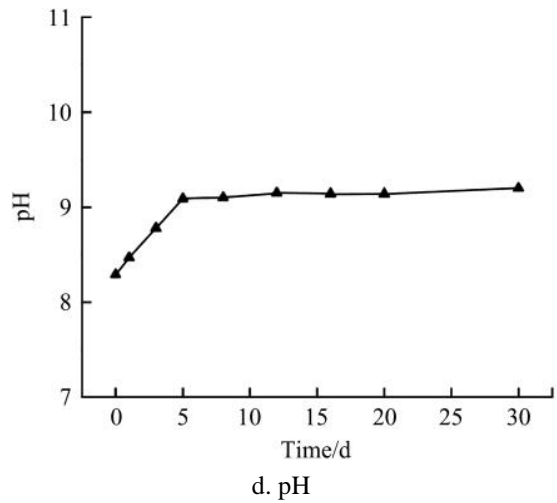

Figure 1 Physical and chemical characteristics change during pig manure composting

\subsection{Microbial succession during composting}

3.2.1 Richness and diversity of bacterial and fungal species

In the study, a total of 1301 OTUs of bacterial and 812 OTUs of fungal species were obtained from the compost samples. The diversities of bacterial community in the samples were indicated using the $\alpha$-diversity indexes ${ }^{[24]}$. The Shannon and Simpson indexes (Table 2) were determined. Sengupta et al. ${ }^{[25]}$ demonstrated that a higher Shannon Index and lower Simpson Index indicated a higher microbial uniformity. During the composting process, the Shannon Index was seen to increase during the mesophilic phase, with a peak value for the bacterial community being achieved on D3 and for the fungal community on D5. Alternatively, the Simpson Index was observed to decrease during the mesophilic phase followed by an increase. During the cooling phase, the bacterial diversity decreased due to the readily biodegradable organic matter that had decomposed ${ }^{[26]}$. The Chao and Ace indexes also indicated that the bacterial community increased in the mesophilic phase and reached its peak value on D1, and then subsequently decreased during the remaining composting process. The same trend was observed for the Chao and Ace indexes for the fungal community, which reached its peak value on D3.

Table $2 \alpha$ diversity indexes of bacterial and fungal communities in composting samples

\begin{tabular}{|c|c|c|c|c|c|c|c|c|}
\hline \multirow{2}{*}{ Time } & \multicolumn{4}{|c|}{ Bacteria } & \multicolumn{4}{|c|}{ Fungi } \\
\hline & Shannon & Simpson & Ace & Chao & Shannon & Simpson & Ace & Chao \\
\hline D0 & 2.75 & 0.24 & 665.16 & 680.01 & 3.05 & 0.09 & 267.61 & 272.14 \\
\hline D1 & 3.72 & 0.09 & 938.03 & 924.00 & 2.44 & 0.25 & 268.11 & 270.23 \\
\hline D3 & 3.82 & 0.06 & 697.37 & 725.88 & 3.48 & 0.06 & 289.35 & 286.38 \\
\hline D5 & 2.85 & 0.13 & 584.01 & 503.03 & 3.76 & 0.04 & 238.82 & 241.00 \\
\hline D8 & 3.68 & 0.05 & 444.39 & 449.21 & 1.55 & 0.35 & 156.12 & 157.11 \\
\hline D12 & 3.24 & 0.10 & 529.18 & 540.87 & 1.23 & 0.42 & 102.57 & 99.08 \\
\hline D16 & 2.75 & 0.19 & 372.12 & 384.00 & 1.05 & 0.44 & 103.66 & 101.59 \\
\hline D30 & 3.73 & 0.06 & 381.04 & 400.24 & 1.48 & 0.43 & 149.57 & 148.55 \\
\hline
\end{tabular}

\subsubsection{Composition of bacterial communities}

The bacterial community plays a key role in maintaining an ecological environment ${ }^{[27]}$. Thus, by comparing the composition and structure of the various bacterial 16S rRNA genes obtained via high-throughput sequencing, the compositional changes of the bacterial community during composting were analyzed. The composition of bacterial communities revealed distinct variations during the composting process at the phylum level. Firmicutes, Proteobacteria, Bacteroidetes, and Actinobacteria were the four most dominant phyla present during the entire composting process, which was similar to the results observed in the studies performed by Jing et al. ${ }^{[28]}$ and Rui et al. ${ }^{[29]}$. The Firmicutes spp. was the most abundant among the four phyla, and increased to account for $97.12 \%$ of the total sequences on D5, followed by a decrease to $31.67 \%$ on D30. The percentages of Actinobacteria spp. increased significantly during the thermophilic phase, accounting for $11.59 \%$ and $15.64 \%$ on D1 and D3, respectively, followed by decreased expression on D5, and a subsequent rebound to $23.85 \%$ on D30. In addition, the percentage of Bacteroidetes spp. increased to $30.74 \%$ thereby accounting for one of the dominant phyla along with Firmicutes spp. Lastly, the percentage of Proteobacteria spp. was seen to decrease during the thermophilic phase, followed by an increase during the cooling phase, and subsequent increase to $13.52 \%$. Takaku et al. ${ }^{[30]}$ also demonstrated that the percentage of Bacteroidetes spp. increased during the cooling phase, and Rui et al. demonstrated that the percentage of Actinobacteria spp. could be indicative of the humification of composting ${ }^{[29]}$.

The diversity of bacterial genera was also analyzed (Figure 2). Clostridium sensu stricto (49.74\%, Firmicutes), Terrisporobacter (18.23\%, Firmicutes), Turicibacter (2.87\%, Firmicutes), Lactobacillus (2.75\%, Firmicutes), and Anaerococcus (2.24\%, Firmicutes) were the most prominent genera identified at the commencement of the composting process. However, the number of Clostridium sensu stricto and Terrisporobacter species was seen 
to decrease significantly during the thermophilic phase to $5.45 \%$ and $0.97 \%$ on D5, respectively. Chen et al. ${ }^{[31]}$ reported that the genera Clostridium sensu stricto were the dominant Firmicutes in pig manure composting. Alternatively, Lactobacillus and Sinibacillus species increased significantly to $10.80 \%$ and $30.71 \%$ on D5, respectively. During the cooling phase, the percentage of Sporosarcina increased to $61.13 \%$ on D16, however, decreased to $6.07 \%$ by the end of the composting process. Actinomadura
(Actinobacteria), Sporosarcina (Firmicutes), norank $f$ Sphingobacteriaceae (Bacteroidetes), and Sinibacillus (Firmicutes) increased to $21.51 \%, 6.07 \%, 5.86 \%$, and $5.61 \%$, respectively. PCoA results revealed that for samples obtained prior to self-heating (D0, D1 and D3), during the cooling phase (D5-D16), and in mature compost (D30) clustered to three individual groups (Figure 3a). The first two PCs explained $65.72 \%$ of the variance of the bacterial communities.

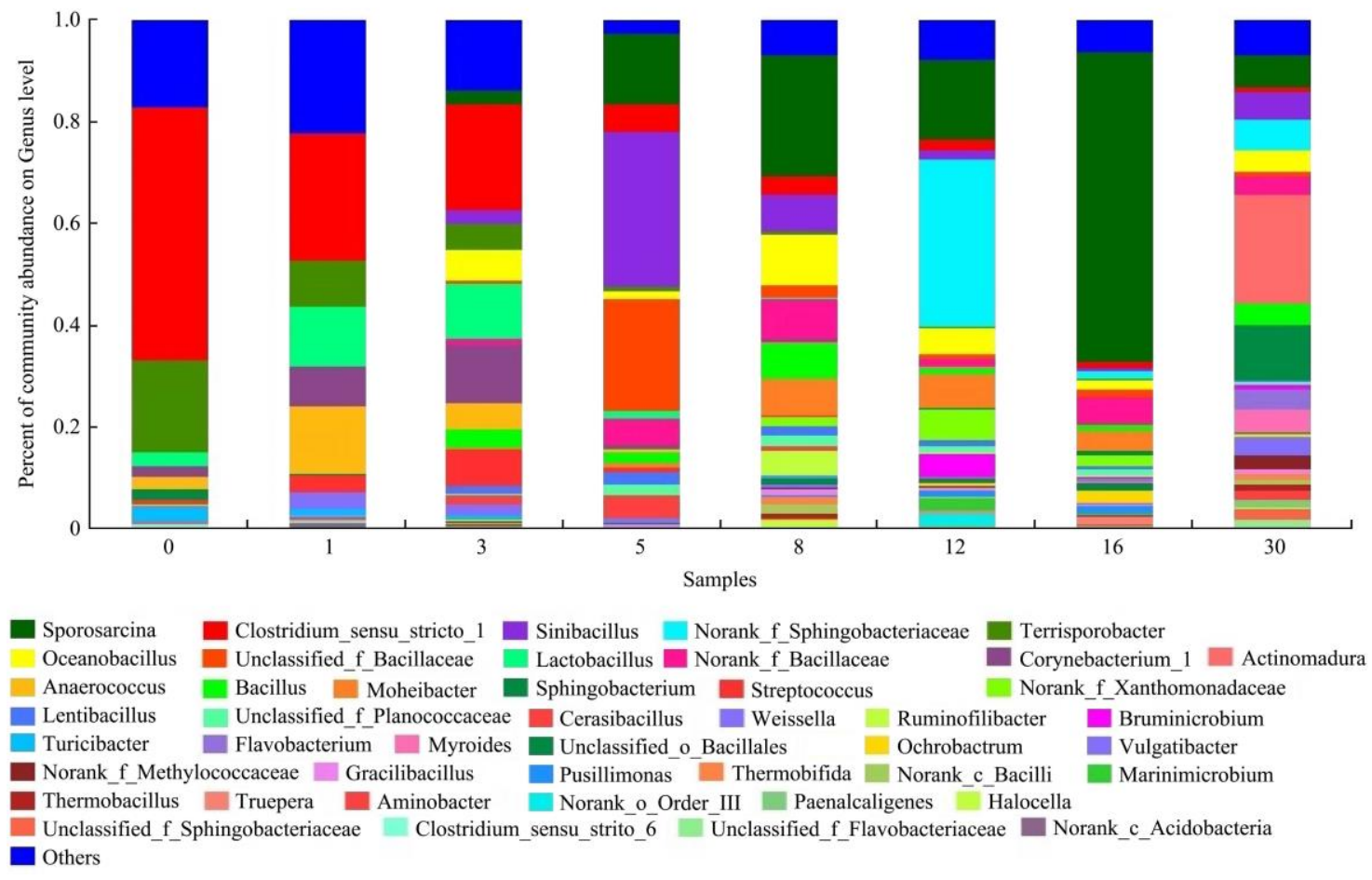

Figure 2 Percentage of bacterial communities and their genera distribution in different composting stages

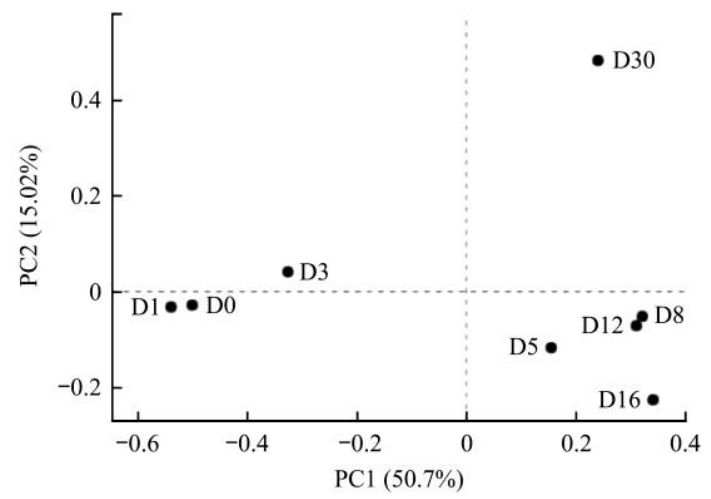

a.

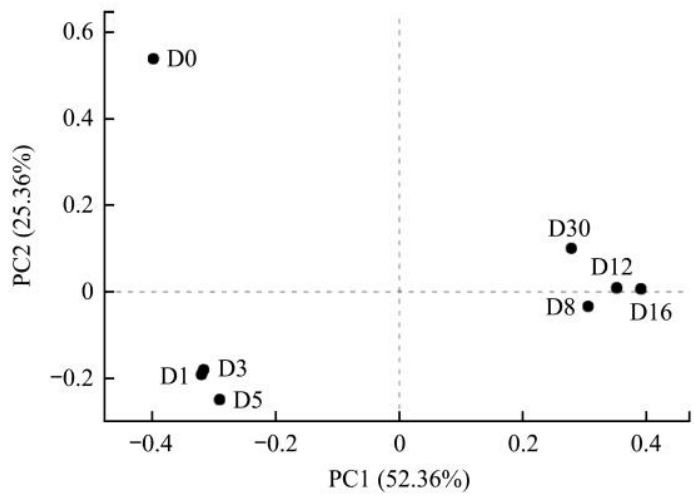

b.

Figure 3 Principal coordinate analysis (PCoA) on genera showing potentially correlated variables of the a) bacterial and b) fungal distribution pattern

\subsubsection{Composition of fungal communities}

Ascomycota was the most dominant phylum of fungal species, which accounted for $90.87 \%$ in the initial composting material, and decreased to $83.65 \%$ (D5) during the mesophilic phase, and then increased to above $97 \%$ during the cooling phase. The percentage of unclassified_k_Fungi increased from $0.16 \%$ to $7.33 \%$ on D1. The percentage of Basidiomycota also increased to $2.33 \%$ and $3.80 \%$ on D5 and D8, respectively and then decreased again and Zygomycota increased to $4.44 \%$ on D5. Additionally, the percentage of Ascomycota increased to $97.8 \%$ in the mature compost. The fungal composition was complex within the initial material, and the dominant fungal species were found to be Alternaria (18.36\%), Meyerozyma (14.25\%), Gibberella
(12.28\%), Sarocladium (8.93\%), Acremonium (7.79\%), and Candida (6.79\%). Aspergillus spp. (Ascomycota) increased dramatically during the composting process to $52.16 \%$ and $43.71 \%$ on D3 and D5, respectively, and then decreased again to $3.85 \%$ in the final mature compost. During the cooling phase, unclassified_o_Sordariales was observed to increase to $43.25 \%$ on D8, thus becoming the dominant fungal order, and further increased to $63.82 \%$ in the mature compost. The percentage of Thermomyces increased to $43.83 \%$ on D8 and decreased to $11.41 \%$ in the mature compost. PCoA demonstrated that samples obtained prior to self-heating (D0, D1 and D3), during the cooling phase (D5 and D16), and in the mature compost (D30) clustered into three separate groups (Figure $3 \mathrm{~b}$ ). The first two 
principal coordinates accounted for $77.72 \%$ of the variance

observed within the bacterial communities.
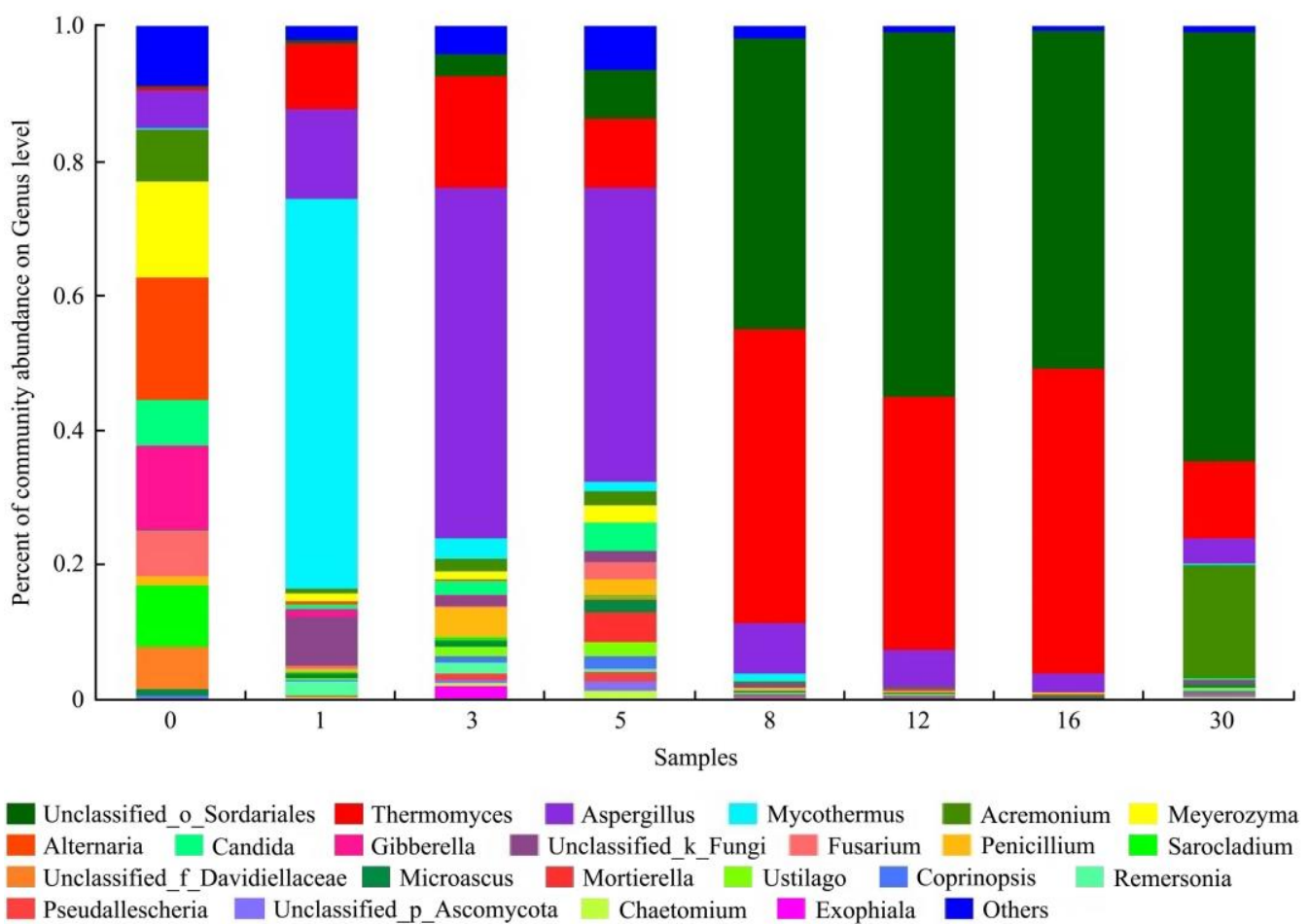

Figure 4 Percentage of fungal communities and their genera distribution in different composting stages

\subsection{The evolution of the distribution of heavy metals}

During the composting process, the total content of heavy metals such as $\mathrm{Cu}, \mathrm{Zn}, \mathrm{Cd}$, and $\mathrm{Pb}$ increased to $363.40,1196.92$, 0.16 , and $6.18 \mathrm{mg} / \mathrm{kg}$ from $245.00,1231.79,0.13$, and $2.17 \mathrm{mg} / \mathrm{kg}$, respectively, which may have been caused by the weight loss in the compost pile throughout the entire 30 days process $^{[1,32]}$. Additionally, analysis of the heavy metal distribution is one of the methods for evaluating the risk of heavy metals ${ }^{[6,33]}$. The exchangeable fraction of heavy metals such as $\mathrm{Cu}, \mathrm{Zn}, \mathrm{Cd}$, and $\mathrm{Pb}$ had the highest mobility and bioavailability among the extractable fractions ${ }^{[1]}$. During the composting process, the exchangeable fraction of $\mathrm{Cu}$ decreased from $43.90 \%$ to $14.91 \%$ (Figure 5a) and the inactivation rate of $\mathrm{Cu}$ was found to be $46.99 \%$, which was higher than that in our previous work without the addition of EM $(40.28 \%)^{[6]}$. In addition, the reduction fraction of $\mathrm{Cu}$ was also found to decrease. The oxidation fraction and residual fraction of $\mathrm{Cu}$ increased to $22.48 \%$ and $50.63 \%$, respectively in the compost. The exchangeable fraction for $\mathrm{Zn}$ also demonstrated a slight decrease within the compost (Figure 5b). The oxidation fraction reduced from $29.71 \%$ to $11.55 \%$, while the reduction fraction and residual fraction for $\mathrm{Zn}$ increased to $40.34 \%$ and $26.39 \%$, respectively. The percentage of exchangeable fraction for $\mathrm{Pb}$ showed a high inactivation rate of $60.79 \%$, decreasing from $24.99 \%$ to $8.21 \%$, and the reduction fraction percentage decreased from $32.43 \%$ to $10.64 \%$, while the residual fraction increased to $75.92 \%$ (Figure 5c). Alternatively, $\mathrm{Cd}$ was found primarily in the oxidation and residual fractions of the composting material, and the residual fraction increased from $7.82 \%$ to $17.88 \%$ (Figure $5 \mathrm{~d}$ ). Zeng et al. ${ }^{[34]}$ demonstrated that the presence of dissolved organic matter in soil may increase the mobility and uptake of heavy metals to plant roots. However, controversially, Hanc et al. ${ }^{[35]}$ observed a decrease of $11 \%$ in the exchangeable fraction of $\mathrm{Cd}$ within household biowaste.

\subsection{Effect of EM on heavy metal revolution}

The relationships between the different fractions of heavy metals and functional bacterial and fungal communities are shown in Figure 6. The residual fraction percentage for $\mathrm{Cu}$ was determined to be significantly related to bacteria such as Actinomadura, and norank_f_Sphingobacterialceae $(p<0.05)$, as well as to the fungal species identified as unclassified_Sordariales $(p<0.05)$. The percentage of exchangeable fraction for $\mathrm{Cu}$ demonstrated a significant positive relationship with Sarocladium, Fusarium, Penicillium $(p<0.01)$, Microascus, Meyerozyma, Candida, Aspergillus, and Coprinopsis $(p<0.05)$, which all decreased during composting. The reduction fraction percentage for $\mathrm{Zn}$ also revealed a significant negative correlation with Terrisporobacter $(p<0.05)$, Clostridium_sensu_stricto $(p<0.05)$, and norank Sphingobacteriaceae $(p<0.05)$, while the residual fraction percentage for $\mathrm{Zn}$ demonstrated a significant positive correlation with Sphingobacterium $(p<0.01)$. Additionally, the oxidation fraction of $\mathrm{Zn}$ was positively related to the percentage of Aspergillus $(p<0.01)$. The exchangeable fraction and oxidation fraction of $\mathrm{Pb}$ revelated negative relationships with norank Sphingobacteriaceae $(p<0.01)$, while the residual fraction demonstrated a positive correlation. The oxidation fraction percentage for $\mathrm{Pb}$ was positively related to Corynebacterium, Lactobacillus, Streptococcus, Anaerococcus, Terrisporobacter, and Clostridium_sensu_stricto $(p<0.001)$. The oxidation fraction percentage for $\mathrm{Pb}$ revealed a negative correlation with unclassified_Sordariales, while the residual fraction of $\mathrm{Pb}$ showed a positive relationship. The percentage of the fungal genera, Aspergillus $\quad(p<0.001), \quad$ Penicillium $\quad(p<0.05), \quad$ Mycothermus $(p<0.05)$, and Remersoinia $(p<0.05)$ all demonstrated positive correlation with the oxidation fraction of $\mathrm{Pb}$. Additionally, the residual fraction percentage for $\mathrm{Pb}$ was found to be significantly related to norank $f$ Sphingobacteriaceae $(p<0.01)$. The exchangeable fraction of $\mathrm{Cd}$ demonstrated a significant negative correlation with clostridium_sensu_stricto $(p<0.001)$ while the oxidation fraction revealed a positive correlation. In addition, the exchangeable fraction and residual fraction of $\mathrm{Cd}$ both showed 

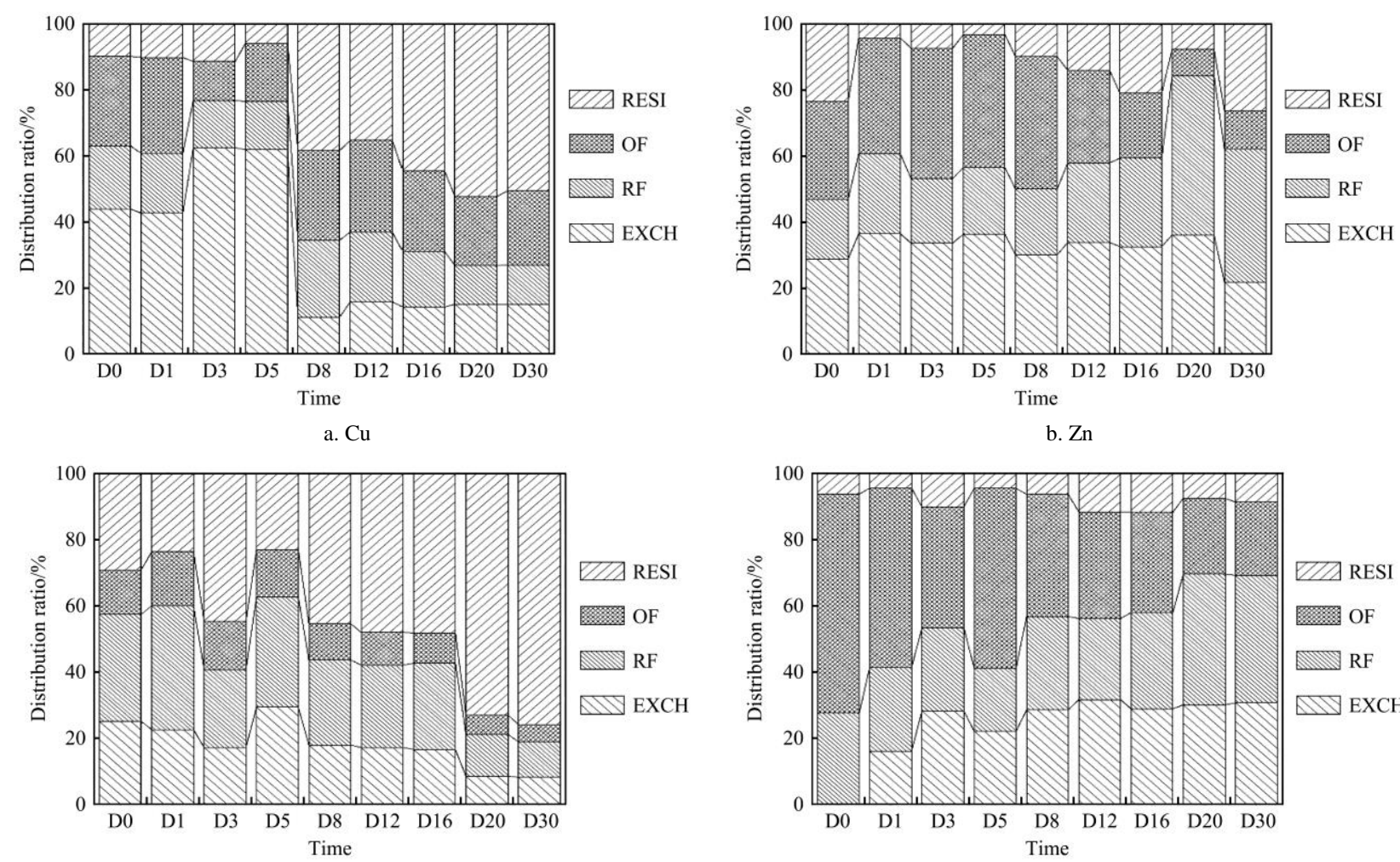

b. $\mathrm{Zn}$

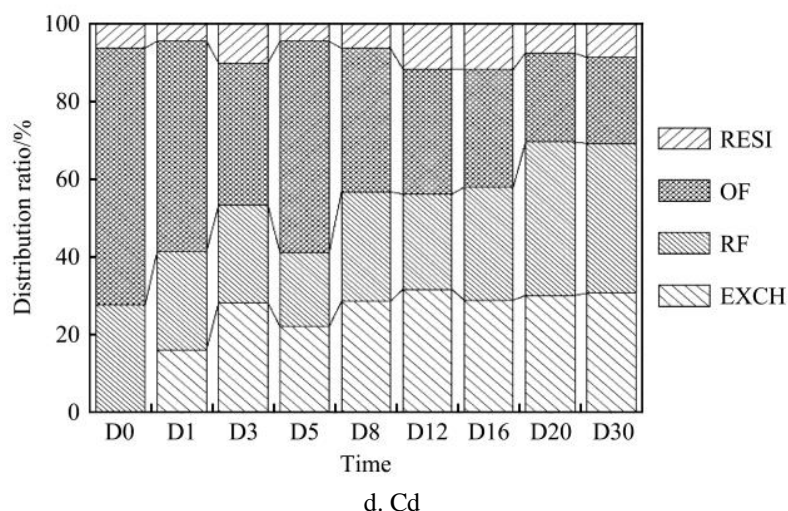

Figure 5 Variation in the percentage of heavy metals fractions during the composting process

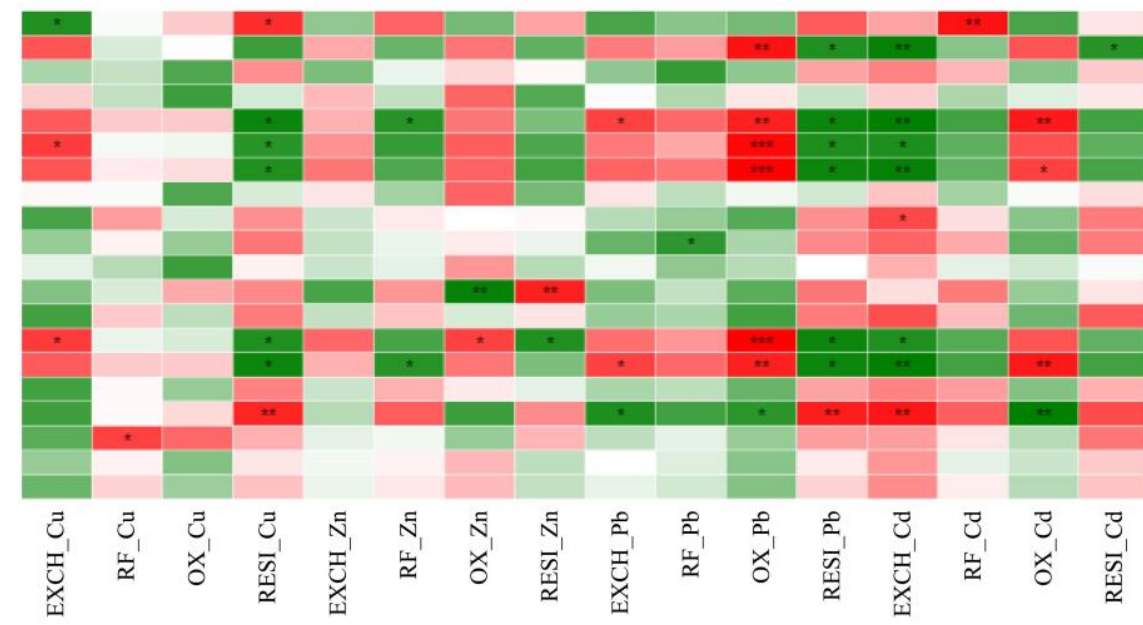

Actinomadura Anaeroco

Cerasibacillus

Clostridium_sensu_stricto_1

Corynebacterium_ 1

Lactobacillus

Lentibacillus

Moheibacter

Sinibacillus

Sphingobacterium

Sporosarcina

Streptococcus

Terrisporobacter

Norank $f$ Bacillaceae

Norank_f_Sphingobacteriaceae

Norank f Xanthomonadaceae

Unclassified $f$ Bacillaceae

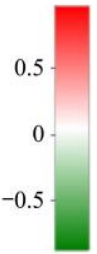

Unclassified f Planococcaceae

a.
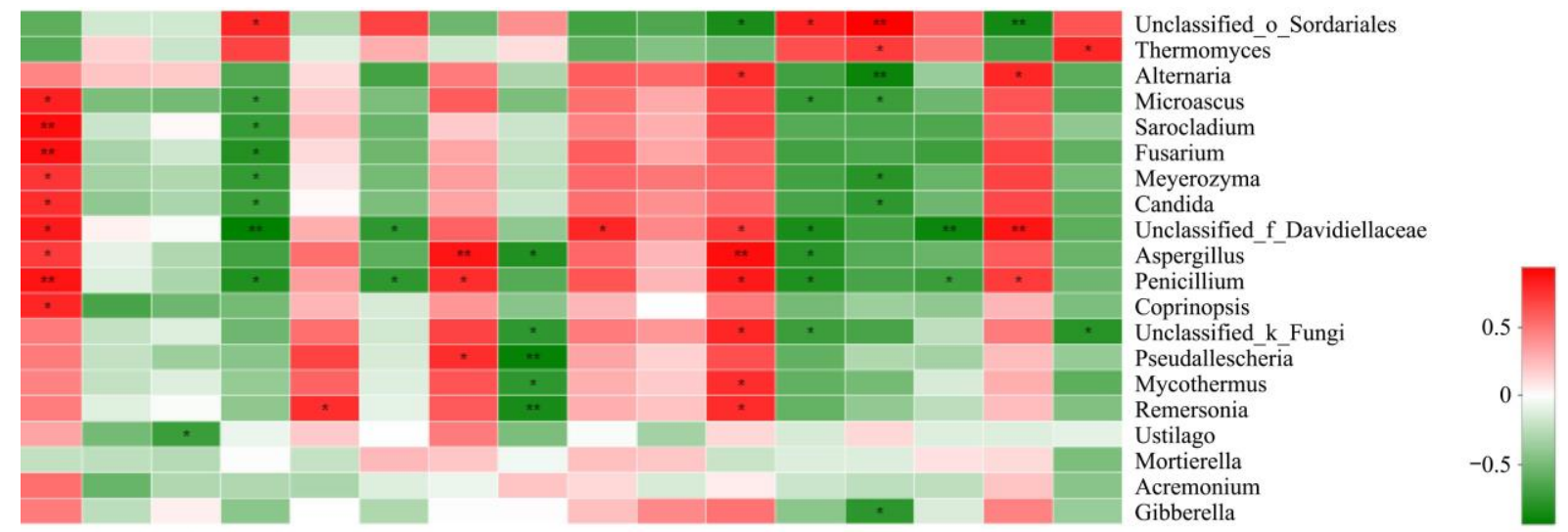

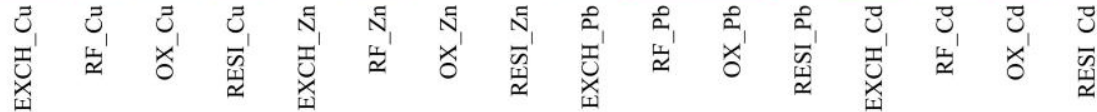

b.

Note: $R$ is represented by different colors. Positive $r$ values are shown in shades of red and negative values in shades of blue. $\quad * p<0.05, * * p<0.01, * * * p<0.001$.

Figure 6 Correlation heat map of the top 20 genera in a) bacterial and b) fungal communities and the percentage of four heavy metal fractions 
significant negative correlation with Anaerococcus $(p<0.001)$, which was decreased during composting, while the oxidation fraction showed a positive relationship. The EM inoculated in this research was mainly consisted of Lactobacillus spp., yeast species, Bacillus spp., photosynthetic bacteria, and Actinomycetes spp.. During the composting process, Lactobacillus was positively correlated with the oxidation fraction of $\mathrm{Pb}(p<0.001)$ and the oxidation fraction of $\mathrm{Cd}(p<0.001)$.

Among the related bacterial, Clostridium (sensu_stricto_1) is widely distributed in compost, soil ${ }^{[36]}$, however, the effect of the bacterial community on $\mathrm{Cu}$ toxicity has not been discussed. However, previous studies mostly focused on heavy metals in solutions, such as Sporosarcina pasteurii could eliminate $\mathrm{Pb}$ and $\mathrm{Zn}$. Bacterial that generates urease enzymes could cause metal ions to precipitate through the hydrolysis of urea into one mole of carbonate and two moles of ammonia per mole of urea ${ }^{[37]}$. Clostridium spp. was found to accelerate the utilization of cellulose during composting, which could improve the fermentation process to reduce $\mathrm{Cu}$ toxicity. Few studies have discussed the influence of other bacterial on heavy metal succession in composting. And among fungal, the correlation between heavy metal changes was regarded as the indirect influence through the biodegradation of organic matters and the formation of complex compounds. Mycothermus has a considerable capacity for cellulose and hemicellulose degradation, as well as producing various thermostable enzymes including amylase, cellulase, lipase, and xylanase $^{[38]}$. Aspergillus possesses various coding genes of the glycoside hydrolase family and auxiliary activity family involved in lignocellulose degradation ${ }^{[39,40]}$, which could improve the process of heavy metal passivation. Few reports have discussed the influence of other fungal on the heavy metal succession. Further research is also needed on the pathways of effects of fungal communities on heavy metals passivation.

\section{Conclusions}

This study was performed to investigate the effect of addition of EM on the microbial community and the bio-availability of heavy metals during pig manure composting. The compost met the requirement for harmlessness with a germination index of $96.42 \%$. The overall diversity in bacterial and fungal species decreased throughout the composting process. The bioavailability of $\mathrm{Cu}$ and $\mathrm{Pb}$ also decreased significantly during composting. And the change of heavy metals bioavailability showed significant correlation with the change of bacterial and fungal community structure. But the mechanism of the influence of microbial community change on the heavy metal passivation needs further investigation.

\section{Acknowledgements}

The project was financially supported by the National Key R\&D Program of China (2018YFD0500205).

\section{[References]}

[1] Shen Y J, Zhao L X, Meng H B, Hou Y Q, Zhou H B, Wang F, et al. Effect of aeration rate, moisture content and composting period on availability of copper and lead during pig manure composting. Waste Management \& Research, 2016; 34(6): 578-583.

[2] Wang F, Zhao L X, Shen Y J, Meng H B, Xiang X, Cheng H, et al. Analysis of heavy metal contents and source tracing in organic fertilizer from livestock manure in North China. Transactions of the CSAE, 2013; 29(19): 202-208. (in Chinese)
[3] Guntinas M B D L C, Semeraro A, Wysocka I, Cordeiro F, Quétel C, Emteborg $\mathrm{H}$, et al. Proficiency test for the determination of heavy metals in mineral feed. The importance of correctly selecting the certified reference materials during method validation. Food Additives \& Contaminants, 2011; 28(11): 1534-1546.

[4] Meng J, Lu W, Zhong L, Liu X, Brookes P C, Xu J, et al. Contrasting effects of composting and pyrolysis on bioavailability and speciation of $\mathrm{Cu}$ and $\mathrm{Zn}$ in pig manure. Chemosphere, 2017; 180: 93-99.

[5] Zheng G D, Ding G, Chen T B, Wei L. Stabilization of nickel and chromium in sewage sludge during aerobic composting. Journal of Hazardous Materials, 2007; 142(1-2): 216-221.

[6] Zhou H B, Meng H B, Zhao L X, Shen Y J, Hou Y Q, Cheng H S, et al Effect of biochar and humic acid on the copper, lead, and cadmium passivation during composting. Bioresource Technology, 2018; 258: 279-286.

[7] Baldrian P. Interactions of heavy metals with white-rot fungi. Enzyme and Microbial Technology, 2003; 32(1): 78-91.

[8] Gülay B L, Sema B, M Yakup A. Biosorption of heavy metal ions on immobilized white-rot fungus Trametes versicolor. Journal of Hazardous Materials, 2003; 101(3): 285-300.

[9] Roy S V, Vanbroekhoven K, Dejonghe W, Diels L. Immobilization of heavy metals in the saturated zone by sorption and in situ bioprecipitation processes. Hydrometallurgy, 2006; 83(1): 195-203.

[10] Say R, Denizli A, Arica M Y. Biosorption of cadmium (II), lead (II) and copper (II) with the filamentous fungus Phanerochaete chrysosporium. Bioresource Technology, 2001; 76(1): 67-70.

[11] Zeng G M, Huang D L, Huang G H, Hu T J, Jiang X Y, Feng C L, et al Composting of lead-contaminated solid waste with inocula of white-rot fungus. Bioresource Technology, 2007; 98(2): 320-326.

[12] Xi B D, He X S, Wei Z M, Jiang Y H, Li M X, Li D, et al. Effect of inoculation methods on the composting efficiency of municipal solid wastes. Chemosphere, 2012; 88(6): 744-750.

[13] Zheljazkov V D, Warman P R. Phytoavailability and fractionation of copper, manganese, and zinc in soil following application of two composts to four crops. Environmental Pollution, 2004; 131(2): 187-195.

[14] Xi B, Liu H, Zeng G, Huang G, Bai Q. Composting MSW and sewage sludge with effective complex microorganisms. Journal of Environmental Sciences, 2002; 14(2): 264-268.

[15] Dach J, Wolnamaruwka A, Zbytek Z. Influence of effective microorganisms addition (EM) on composting process and gaseous emission intensity. Journal of Research \& Applications in Agricultural Engineering, 2009; 54(3): 49-55.

[16] Mupondi L T, Mnkeni P N S, Brutsch M O. The effects of goat manure, sewage sludge and effective microorganisms on the composting of pine bark. Compost Science \& Utilization, 2006; 14(3): 201-210.

[17] Daur I. Study of commercial effective microorganism on composting and dynamics of plant essential metal micronutrients. Journal of Environmental Biology, 2016; 37(5): 937-941.

[18] Tiquia S M, Tam N F Y, Hodgkiss I J. Effects of turning frequency on composting of spent pig-manure sawdust litter. Bioresource Technology, 1997; 62(1-2): 37-42.

[19] Eaton A. Standard methods for the examination of water and wastewater 21st ed, American Public Health Association, 2005. ISBN 9780875530475.

[20] Caporaso J, Kuczynski J, Stombaugh J, Bittinger K, Bushman F. QIIME allows integration and analysis of high-throughput community sequencing data. Nat. Meth. 2010: 335-336.

[21] Edgar R C. Search and clustering orders of magnitude faster than BLAST Bioinformatics, 2010; 26(19): 2460-2461.

[22] Team R D C. R: A language and environment for statistical computing. Vienna, Austria: R Foundation for Statistical Computing, 2010.

[23] Kolde R. pheatmap: Pretty heatmaps. Free Software Foundation, Inc. Boston, USA, 2015.

[24] Huang K, Li F, Wei Y, Chen X, Fu X. Changes of bacterial and fungal community compositions during vermicomposting of vegetable wastes by Eisenia foetida. Bioresource Technology, 2013; 150(4): 235-241.

[25] Sengupta A, Dick W A. Bacterial community diversity in soil under two tillage practices as determined by pyrosequencing. Microbial Ecology, 2015; 70(3): 853-859.

[26] Wu Z Y, Cai L, Krafft T, Gao D, Wang L. Biodrying performance and bacterial community structure under variable and constant aeration regimes during sewage sludge biodrying. Drying Technology, 2017; 36(10): 84-92. 
[27] Garcia-Salamanca A, Molina-Henares M A, Van Dillewijn P, Solano J, Pizarro-Tobias P, Roca A, et al. Bacterial diversity in the rhizosphere of maize and the surrounding carbonate-rich bulk soil. Microb Biotechnol, 2013; 6(1): 36-44.

[28] Tang J C, InoueY, Yasuta T, Yoshida S, Katayama A. Chemical and microbial properties of various compost products. Soil Science and Plant Nutrition, 2003; 49(2): 273-280.

[29] Wang R, Zhang J Y, Sui Q W, Wan H F, Tong J, Chen M X, et al. Effect of red mud addition on tetracycline and copper resistance genes and microbial community during the full scale swine manure composting. Bioresour Technol, 2016; 216(1049-1057.

[30] Takaku H, Kodaira S, Kimoto A, Nashimoto M, Takagi M. Microbial communities in the garbage composting with rice hull as an amendment revealed by culture-dependent and -independent approaches. Journal of Bioscience \& Bioengineering, 2006; 101(1): 42-50.

[31] Chen Z, Wang Y, Wen Q. Effects of chlortetracycline on the fate of multi-antibiotic resistance genes and the microbial community during swine manure composting. Environmental Pollution, 2017; 237: 977-987.

[32] Liu Y, Ma L, Li Y, Zheng L. Evolution of heavy metal speciation during the aerobic composting process of sewage sludge. Chemosphere, 2007; 67(5): 1025-1032.

[33] Cao X, Ma L Q, Chen M, Singh S P, Harris W G. Impacts of phosphate amendments on lead biogeochemistry at a contaminated site. International Journal of Environmental Science and Technology, 2002; 36(24): 5296-5304.
[34] Zeng F, Ali S, Zhang H, Ouyang Y, Qiu B, Wu F, et al. The influence of $\mathrm{pH}$ and organic matter content in paddy soil on heavy metal availability and their uptake by rice plants. Environmental Pollution, 2011; 159(1): 84-91.

[35] Hanc A, Szakova J, Ochecova P. Differences in the mobility of $\mathrm{Cd}, \mathrm{Cu}$, $\mathrm{Pb}$ and $\mathrm{Zn}$ during composting of two types of household bio-waste collected in four seasons. Bioresource Technology, 2014; 168(3): 204-213.

[36] Yin Y, Gu J, Wang X, Song W, Zhang K, Sun W, et al. Effects of copper addition on copper resistance, antibiotic resistance genes, and intl1 during swine manure composting. Frontiers in Microbiology, 2017; 8: 344.

[37] Burbank M B, Weaver T J, Williams B C, Crawford R L. Urease activity of ureolytic bacteria isolated from six soils in which calcite was precipitated by indigenous bacteria. Geomicrobiology Journal, 2012; 29(4): 389-395.

[38] Basotra N, Kaur B, Di Falco M, Tsang A, Chadha B S. Mycothermus thermophilus (Syn. Scytalidium thermophilum): Repertoire of a diverse array of efficient cellulases and hemicellulases in the secretome revealed. Bioresource technology, 2016; 222: 413-421.

[39] Wang X, Kong Z, Wang Y, Wang M, Liu D, Shen Q. Insights into the functionality of fungal community during the large scale aerobic co-composting process of swine manure and rice straw. Journal of Environmental Management, 2020; 270: 110958.

[40] Adav S S, Ravindran A, Sze S K. Quantitative proteomic study of Aspergillus fumigatus secretome revealed deamidation of secretory enzymes. Journal of Proteomics, 2015; 119: 154-168. 